\title{
Schottky-based band lineups for refractory semiconductors
}

\author{
M. W. Wang, J. O. McCaldin, J. F. Swenberg, and T. C. McGill ${ }^{\text {a) }}$ \\ T. J. Watson, Sr., Laboratory of Applied Physics, California Institute of Technology, \\ Pasadena, California 91125
}

R. J. Hauenstein

Physics Department, Oklahoma State University, Stillwater, Oklahoma 74078

(Received 5 December 1994; accepted for publication 26 January 1995)

\begin{abstract}
An overview is presented of band alignments for small-lattice parameter, refractory semiconductors. The band alignments are estimated empirically through the use of available Schottky barrier height data, and are compared to theoretically predicted values. Results for tetrahedrally bonded semiconductors with lattice constant values in the range from $\mathrm{C}$ through $\mathrm{ZnSe}$ are presented. Based on the estimated band alignments and the recently demonstrated p-type dopability of GaN, we propose three novel heterojunction schemes which seek to address inherent difficulties in doping or electrical contact to wide-gap semiconductors such as $\mathrm{ZnO}, \mathrm{ZnSe}$, and $\mathrm{ZnS}$. (C) 1995 American Institute of Physics.
\end{abstract}

This letter presents Schottky barrier based estimates of band alignments among tetrahedrally bonded semiconductors with lattice constant values in the range from $\mathrm{C}$ to $\mathrm{ZnSe}$. This range includes the refractory semiconductors, e.g., GaN and related nitride compounds, of much current interest due to recent successes in short-wavelength light-emitting devices. ${ }^{1}$ The band alignments are determined empirically from $\mathrm{Au}$ Schottky barrier height data in a manner similar to that found in Refs. 2 and 3. Basis for the connection between band alignments and Schottky barrier height data can be found in Ref. 4. For our study, we use primarily the limited Schottky barrier data currently available, which nonetheless appear sufficient to indicate some striking differences between small and large lattice-parameter semiconductors. These Schottkybased band edge energies are compared to the predictions of Harrison and Tersoff..$^{5}$ Based on our findings for valence band offsets of wide-gap semiconductors, three applications, each involving heterostructures of $p$-type $\mathrm{GaN}$ with wide-gap II-VI semiconductors, are proposed as a means of circumventing limitations in $p$-type dopability or electrical contact formation in the latter materials.

The band alignments are summarized in Fig. 1. The data are presented in the form of a "McCaldin" diagram, ${ }^{6}$ which simultaneously displays lattice parameters, band gaps, band alignments, and dopability. Each semiconductor is represented by a vertical line whose length is determined by the band gap of the semiconductor and whose vertical position is determined by experimental Au Schottky barrier height measurements from the literature, where the zero of energy is defined as the Au Fermi level. The $n$-type dopability is indicated by open and filled triangles for either undopable or dopable material, respectively. Similarly, open and filled squares are used to indicate $p$-type dopability. In cases where only the conduction-band Schottky barrier height $\phi_{B n}$, was measured, the valence-band Schottky barrier height, $\phi_{B p}$, was determined using $E_{g}=\phi_{B n}+\phi_{B p}$, where $E_{g}$ is the semiconductor band gap.

${ }^{a)}$ Electronic mail: tcm@ssdp.caltech.edu
Also shown in Fig. 1 are the band lineups as determined from theoretical predictions of Harrison and Tersoff. These values are indicated by horizontal bars representing the valence band edge. When the predicted $E_{v}$ lies below the experimental $E_{v}$, a vertical dotted line connects the horizontal bar to the symbol for the experimental $E_{v}$. For clarity, the theoretically determined conduction band edge positions are not shown. It should be noted that with the exception of a few semiconductors, the calculated $E_{v}$ values of Ref. 5 are in reasonable agreement with the experimental values, and that discrepancies can generally be explained by the lack of $d$-orbitals in the calculation. All of the values used to produce Fig. 1 are also listed in Table I. ${ }^{3,5,7-35}$

A few points should be made regarding the experimental band lineup values. For AlN and AlP, no Schottky barrier height data were available, so the valence band edge positions were determined from measurements of the AlN/ $\mathrm{GaN}^{26,27}$ and $\mathrm{AlP} / \mathrm{GaP}^{33}$ valence band offsets, respectively. For InN, no experimental data were found, so only the calculated band alignment is shown. Other non-Schottky-based measurements suggest that GaN and AlN should lie higher in the diagram, ${ }^{36,37}$ but we use the Au Schottky barrier height result. $^{28}$ Finally, the equilibrium crystal structure of some of the semiconductors is wurzite instead of zinc blende. For these semiconductors, we use the band gap for the wurzite crystal structure; however, for clarity of presentation, we use the lattice constant for the equivalent zinc blende crystal structure. For $\mathrm{SiC}$, the $3 \mathrm{C}-\mathrm{SiC}$ band gap and lattice parameter are used. We expect little variation of the $E_{v}$ values with crystal structure, since the SiC Schottky barrier height data do not show a strong dependence of the valence band position on crystal structure, as supported by the recent measurement of a small valence band discontinuity between $3 \mathrm{C}-\mathrm{SiC}$ and $6 \mathrm{H}-\mathrm{SiC}{ }^{38}$

Figure 1 shows a similar correlation between dopability and band edge position as observed in earlier studies for larger lattice parameter semiconductors. ${ }^{6}$ A notable exception, however, is $\mathrm{GaN}$ which is dopable $p$-type to high levels despite a deep valence band edge. Some possible light emit- 


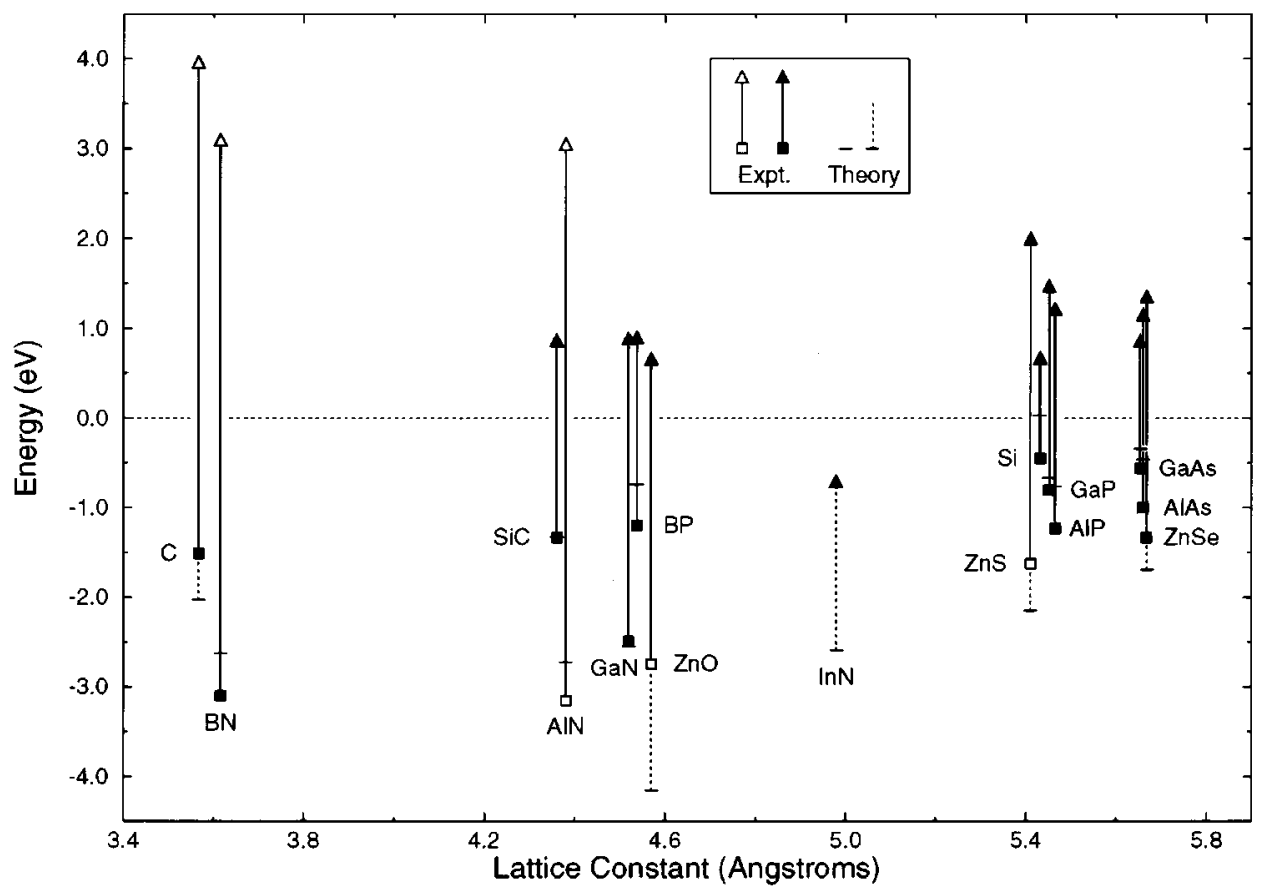

FIG. 1. Diagram for small-lattice parameter tetrahedral semiconductors. Band gaps and band lineups are given by the length and vertical position of the line associated with each semiconductor. Filled and open symbols represent dopable and undopable material, respectively: triangles for $n$-type and squares for $p$-type. Experimental band lineups were determined primarily from Schottky barrier height measurements. The theoretical $E_{v}$ positions of Harrison and Tersoff (Ref. 5) are indicated by horizontal bars.

ter applications utilizing this $p$-type dopability of $\mathrm{GaN}$ are described below.

Graded injector: As explained in detail in Refs. 39 and 40, a suitably designed graded layer near a heterojunction facilitates carrier injection into a semiconductor which is not easily doped with a given carrier type. For example, holes could be injected into $\mathrm{ZnO}$ by transport over a small energy barrier from an adjacent layer of $\mathrm{GaN}$, which happens to have a relatively good lattice match to $\mathrm{ZnO}$. The flatband diagram for a $p$-GaN $/ n-\mathrm{ZnO}$ heterojunction shows a moderate barrier for hole injection from $p-\mathrm{GaN}$ into $n-\mathrm{ZnO}$. This barrier can be overcome by grading the $\mathrm{GaN}$ into an $\mathrm{Al}_{x} \mathrm{Ga}_{1-} \mathrm{N}$ ternary to extend the valence band edge to match that of $\mathrm{ZnO}$ at the $\mathrm{Al}_{x} \mathrm{Ga}_{1-x} \mathrm{~N} / \mathrm{ZnO}$ interface. At the same time, the expanded band gap serves to block electron injection from $n-\mathrm{ZnO}$ into $\mathrm{GaN}$. $p$-GaN/n-ZnO is a typical type II heterojunction with barriers to both carrier types, and grading in this manner allows suppression of one carrier flow while enhancing the other. Note that the graded injector approach does not require doping within the graded region.

Type II, no-barrier injector: As has been discussed previously, ${ }^{41}$ it is possible to have a type II heterojunction with no barrier for either carrier type when at flatband. Figure 1 indicates excellent prospects for this no-barrier application for $n-\mathrm{ZnSe} / p-\mathrm{GaN}$ and $n-\mathrm{ZnS} / p$-GaN heterojunctions. Of these two, $n-\mathrm{ZnS} / p$-GaN is particularly attractive because $\mathrm{ZnS}$ has not yet been rendered $p$-type. While $\mathrm{ZnSe}$ has been made $p$-type, $n$-ZnSe/ $p$-GaN could provide an alternative approach to introducing holes into $n-\mathrm{ZnSe}$. Both of these examples entail large lattice mismatch at the heterojunction, of the same order as in growing GaN on sapphire. Singlecrystal growth has been achieved in the latter case, although
TABLE I. Data for important elemental and binary compound semiconductors with equivalent zinc blende lattice parameters of $5.7 \AA$ or less.

\begin{tabular}{|c|c|c|c|c|}
\hline \multirow[b]{2}{*}{ Material } & \multirow{2}{*}{$\begin{array}{l}\text { Lat. const } \\
(\AA)^{\mathrm{a}}\end{array}$} & \multirow{2}{*}{$\begin{array}{c}\text { Band gap }{ }^{\mathrm{a}} \\
\quad(\mathrm{eV})\end{array}$} & \multicolumn{2}{|c|}{$\phi_{B p}(\mathrm{eV})$} \\
\hline & & & Theory $^{\mathrm{b}}$ & Expt \\
\hline $\mathrm{C}$ & 3.567 & 5.48 & 2.03 & $1.5^{\mathrm{c}}$ \\
\hline $\mathrm{SiC}$ & 4.360 & 2.2 & 1.33 & $1.3^{\mathrm{d}}$ \\
\hline $\mathrm{Si}$ & 5.431 & 1.12 & -0.03 & $0.45^{\mathrm{e}}$ \\
\hline $\mathrm{Ge}$ & 5.658 & 0.66 & -0.32 & $0.07^{\mathrm{e}}$ \\
\hline $\mathrm{BN}$ & 3.616 & $6.2^{f}$ & 2.62 & $3.1^{\mathrm{g}}$ \\
\hline AlN & $4.38^{\mathrm{h}}$ & $6.2^{\mathrm{h}}$ & 2.72 & $3.15^{\mathrm{i}}$ \\
\hline $\mathrm{GaN}$ & $4.52^{\mathrm{h}}$ & $3.39^{\mathrm{h}}$ & 2.55 & $2.50^{\mathrm{j}}$ \\
\hline $\mathrm{InN}$ & $4.98^{h}$ & $1.89^{\mathrm{h}}$ & 2.59 & $\ldots$ \\
\hline $\mathrm{BP}$ & 4.538 & $2.1^{\mathrm{k}}$ & 0.74 & $1.2^{1}$ \\
\hline AlP & 5.464 & 2.45 & 0.76 & $1.23^{\mathrm{m}}$ \\
\hline $\mathrm{GaP}$ & 5.451 & 2.27 & 0.66 & $0.80^{\mathrm{e}}$ \\
\hline InP & 5.869 & 1.35 & 0.77 & $0.86^{\mathrm{e}}$ \\
\hline AlAs & 5.660 & 2.15 & 0.46 & $1.00^{\mathrm{e}}$ \\
\hline GaAs & 5.653 & 1.42 & 0.34 & $0.56^{\mathrm{e}}$ \\
\hline $\mathrm{ZnO}$ & $4.57^{\mathrm{b}}$ & 3.4 & 4.16 & $2.74^{\mathrm{n}}$ \\
\hline $\mathrm{ZnS}$ & 5.41 & 3.62 & 2.16 & $1.62^{\circ}$ \\
\hline $\mathrm{ZnSe}$ & 5.668 & 2.69 & 1.69 & $1.33^{\circ}$ \\
\hline
\end{tabular}

${ }^{\text {aReference }} 7$ unless noted otherwise.

${ }^{\mathrm{b}}$ Reference 5

${ }^{\mathrm{i}}$ References 26,27.

${ }^{c}$ References 8-14.

${ }^{\mathrm{d}}$ References 8,15-21.

${ }^{\mathrm{e}}$ Reference 3.

${ }^{\mathrm{f}}$ References 22-24.

geference 8.

${ }^{\mathrm{h}}$ Reference 25 .
${ }^{\mathrm{j}}$ Reference 28 .

${ }^{\mathrm{k}}$ References 22,29-31.

${ }^{\mathrm{l}}$ Reference 32.

${ }^{\mathrm{m}}$ Reference 33.

${ }^{\mathrm{n}}$ Reference 34.

${ }^{\circ}$ Reference 35 . 
at a cost in terms of imperfections. However, for some device purposes, such imperfections are tolerable, as demonstrated in recent GaN/sapphire blue light emitters. ${ }^{1}$ Furthermore, $\mathrm{ZnS}$ as presently used in electroluminescent devices can tolerate grain boundaries and other imperfections.

Ohmic contacts: In principle, $p$-GaN can introduce holes into any material with $E_{v}$ lying higher in Fig. 1 than $E_{v}$ $(\mathrm{GaN})$. This means that $\mathrm{Ni} / \mathrm{Au}$ on $p-\mathrm{GaN}$, which forms an Ohmic contact, could be used to contact those materials that are dopable $p$-type, but not to levels sufficient for good Ohmic contact. Two examples are $p-\mathrm{GaN} / p-\mathrm{ZnSe}$ and $p$-GaN/p-AlP. In practice, such substrate materials should not be heated above the temperatures at which they were processed, a limitation that may possibly be overcome with the improvement of lower-temperature $\mathrm{GaN}$ growth methods. As with the other applications described above, energetics are favorable for the proposed devices, but practical problems of fabrication remain.

In conclusion, best estimates of band edge energies for smaller lattice parameter semiconductors, based on Schottky barrier heights, have been presented and compared to theoretical estimates. Based on these data, we have proposed three applications which take advantage of the $p$-type dopability of GaN. A graded injector is proposed to facilitate minority carrier injection into $\mathrm{ZnO}$. Type II, no-barrier injectors are proposed using $p-\mathrm{GaN} / n-\mathrm{ZnSe}$ and $p-\mathrm{GaN} / n-\mathrm{ZnS}$ heterojunctions. Finally, $p$-GaN is proposed as a possible Ohmic contacting layer to $p$-ZnSe or $p$-AlP.

This work was supported by the Advanced Research Projects Agency monitored under ONR Contract N0001492-J-1845.

${ }^{1}$ S. Nakamura, T. Mukai, and M. Senoh, Appl. Phys. Lett. 64, 1687 (1994). ${ }^{2}$ E. T. Yu, J. O. McCaldin, and T. C. McGill, Solid State Phys. 46, 1 (1992), see Figs. 4 and 42, and associated text.

${ }^{3}$ S. Tiwari and D. J. Frank, Appl. Phys. Lett. 60, 630 (1992); Commented on by J. O. McCaldin and T. C. McGill, Appl. Phys. Lett. 61, 2243 (1992).

${ }^{4} \mathrm{~J}$. Tersoff, in Heterojunction Band Discontinuities (North-Holland, Amsterdam, 1987), Chap. 1, p. 5.

${ }^{5}$ W. A. Harrison and J. Tersoff, J. Vac. Sci. Technol. B 4, 1068 (1986).

${ }^{6}$ J. O. McCaldin, J. Vac. Sci. Technol. A 8, 1188 (1990).

${ }^{7}$ Landolt-Börnstein, Semiconductors (Springer, Berlin, 1982, 1987), Vols. $17 \mathrm{a}, 17 \mathrm{~b}$, and 22a.

${ }^{8}$ C. A. Mead and W. G. Spitzer, Phys. Rev. A 134, 713 (1964).

${ }^{9}$ G. H. Glover, Solid State Electron. 16, 973 (1973).
${ }^{10}$ E. C. Lightowlers and A. T. Collins, J. Phys. D 9, 951 (1976).

${ }^{11}$ C. A. Mead and T. C. McGill, Phys. Lett. 58A, 249 (1976).

${ }^{12}$ A. Lepek, A. Halperin, and J. Levinson, Phys. Rev. B 19, 2250 (1979).

${ }^{13}$ F. J. Himpsel, P. Heimann, and D. E. Eastman, Solid State Commun. 36, 631 (1980).

${ }^{14}$ M. C. Hicks, C. R. Wronski, S. A. Grot, G. Sh. Gildenblat, A. R. Badzian, T. Badzian, and R. Messier, J. Appl. Phys. 65, 2139 (1989).

${ }^{15}$ S. H. Hagen, J. Appl. Phys. 39, 1458 (1968).

${ }^{16}$ S. Y. Wu and R. B. Campbell, Solid State Electron. 17, 683 (1974).

${ }^{17}$ S. Yoshida, K. Sasaki, E. Sakuma, S. Misawa, and S. Gonda, Appl. Phys. Lett. 46, 766 (1985).

${ }^{18}$ D. E. Ioannou, N. A. Papanicolaou, and P. E. Nordquist, Jr., IEEE Trans. Electron Devices 34, 1694 (1987).

${ }^{19}$ Y. Fujii, M. Shigeta, K. Furukawa, A. Suzuki, and S. Nakajima, J. Appl. Phys. 64, 5020 (1988).

${ }^{20}$ J. R. Waldrop and R. W. Grant, Appl. Phys. Lett. 56, 557 (1990).

${ }^{21}$ J. R. Waldrop, R. W. Grant, Y. C. Wang, and R. F. Davis, J. Appl. Phys. 72, 4757 (1992).

${ }^{22}$ V. A. Fomichev and M. A. Rumsch, J. Phys. Chem. Solids 29, 1015 (1968).

${ }^{23}$ R. M. Chrenko, Solid State Commun. 14, 511 (1974).

${ }^{24}$ N. Miyata, K. Moriki, O. Mishima, M. Fujisawa, and T. Hattori, Phys. Rev. B 40, 12028 (1989).

${ }^{25}$ S. Strite, M. E. Lin, and H. Morkoç, Thin Solid Films 231, 197 (1993).

${ }^{26}$ G. Martin, S. Strite, A. Botchkarev, A. Agarwal, A. Rockett, H. Morkoç, W. R. L. Lambrecht, and B. Segall, Appl. Phys. Lett. 65, 610 (1994).

${ }^{27}$ J. Baur, K. Maier, M. Kunzer, U. Kaufmann, and J. Schneider, Appl. Phys. Lett. 65, 2211 (1994).

${ }^{28}$ P. Hacke, T. Detchprohm, K. Hiramatsu, and N. Sawaki, Appl. Phys. Lett. 63, 2676 (1993).

${ }^{29}$ R. J. Archer, R. Y. Koyama, E. E. Loebner, and R. C. Lucas, Phys. Rev. Lett. 12, 538 (1964).

${ }^{30}$ C. C. Wang, M. Cardona, and A. G. Fischer, RCA Rev. 25, 159 (1964).

${ }^{31}$ G. A. Kurbatov, V. K. Sidorin, and A. M. Acheludchenko, Sov. Phys.Semicond. 17, 7 (1983).

${ }^{32}$ Y. Kumashiro and Y. Okada, Appl. Phys. Lett. 47, 64 (1985).

${ }^{33}$ J. R. Waldrop, R. W. Grant, and E. A. Kraut, J. Vac. Sci. Technol. B 11, 1617 (1993).

${ }^{34}$ R. C. Neville and C. A. Mead, J. Appl. Phys. 41, 3795 (1970).

${ }^{35}$ J. O. McCaldin, T. C. McGill, and C. A. Mead, Phys. Rev. Lett. 36, 56 (1976).

${ }^{36}$ G. Martin, S. Strite, J. Thornton, and H. Morkoç, Appl. Phys. Lett. 58, 2375 (1991).

${ }^{37}$ M. C. Benjamin, C. Wang, R. F. Davis, and R. J. Nemanich, Appl. Phys. Lett. 64, 3288 (1994).

${ }^{38}$ K. F. Dombrowski, U. Kaufmann, M. Kunzer, K. Maier, J. Schneider, V. B. Shields, and M. G. Spencer, Appl. Phys. Lett. 65, 1811 (1994).

${ }^{39}$ M. C. Phillips, M. W. Wang, J. F. Swenberg, J. O. McCaldin, and T. C. McGill, Appl. Phys. Lett. 61, 1962 (1992).

${ }^{40}$ M. W. Wang, M. C. Phillips, J. F. Swenberg, E. T. Yu, J. O. McCaldin, and T. C. McGill, J. Appl. Phys. 73, 4660 (1993).

${ }^{41}$ J. O. McCaldin, Growth and Optical Properties of Wide-Gap II-VI Low Dimensional Semiconductors (Plenum, New York, 1989), pp. 39-51. 